\title{
Exploiting the sequence of naturally occurring elastin: Construction, production and characterization of a recombinant thermoplastic protein- based polymer
}

\author{
R. Machado ${ }^{1}$, A. J. Ribeiro², J. Padrão ${ }^{1}$, D. Silva ${ }^{1}$, A. Nobre ${ }^{1}$, J. A. Teixeira ${ }^{4}$, \\ F. J. Arias ${ }^{2,3}$, A. M. Cunha ${ }^{5}$, J. C. Rodríguez-Cabello ${ }^{2,3}$, M. Casal ${ }^{1 \mathrm{a}}$ \\ ${ }^{1}$ CBMA - Molecular and Environmental Biology Centre, Departament of Biology, University of \\ Minho, Campus de Gualtar, 4710-057 Braga, Portugal \\ ${ }^{2}$ BIOFORGE research group, Dpto. Física de la Materia Condensada, E.T.S.I.I., Universidad de \\ Valladolid, Paseo del Cauce s/n, 47011 Valladolid, Spain \\ ${ }^{3}$ CIBER BBN, Valladolid, Spain \\ ${ }^{4}$ Department of Biological Engineering, University of Minho, Campus de Gualtar, Braga, Portugal \\ ${ }^{5}$ Department of Polymer Engineering, University of Minho, Campus de Azurém, Guimarães, \\ Portugal \\ amcasal@bio.uminho.pt
}

[submitted: 15.04.2009

revised: 23.05 .2009

accepted: 30.05 .2009$]$

Keywords: Elastin-like polymers, VPAVG, nanoparticles, thermoplastic, thermoresponsive polymer.

\begin{abstract}
Genetic engineering was used to produce an elastin-like polymer (ELP) with precise amino acid composition, sequence and length, resulting in the absolute control of MW and stereochemistry. A synthetic monomer DNA sequence encoding for (VPAVG) ${ }_{20}$, was used to build a library of concatemer genes with precise control on sequence and size. The higher molecular weight polymer with 220 repeats of VPAVG was biologically produced in Escherichia coli and purified by hot and cold centrifugation cycles, based on the reversible inverse temperature transition property of ELPs. The use of low cost carbon sources like lactose and glycerol for bacteria cells culture media was explored using Central Composite Design approach allowing optimization of fermentation conditions. Due to its self-assembling behaviour near $33{ }^{\circ} \mathrm{C}$ stable spherical microparticles with a size $\sim 1 \mu \mathrm{m}$ were obtained, redissolving when a strong undercooling is achieved. The polymer produced showed hysteresis behaviour with thermal absorbing/releasing components depending on the salt concentration of the polymer solution.
\end{abstract}

\section{Introduction}

Elastin-like polymers (ELPs) are repetitive polypeptides inspired on the mammalian elastin structure that consists of a pentapeptide repeat, VPGXG, where X, termed the guest residue, is any natural amino acid except proline [1]. The most striking feature of the ELPs is their Inverse Temperature Transition (ITT) behavior. Below a certain critical temperature, the transition temperature $\left(T_{\mathrm{t}}\right)$, and in the presence of water they are soluble, with the polymer chains relatively extended in a disordered state and fully hydrated mainly by hydrophobic hydration [2]. Above $T_{\mathrm{t}}$, the polymer chains hydrophobically fold and adopt a dynamic structure, called $\beta$-spiral, involving one type II $\beta$-turn per pentamer, stabilized by intraspiral inter-turn and inter-spiral hydrophobic contacts $[2,3]$.

The polymer poly(VPAVG), an ELP where the central glycine $(\mathrm{G})$ is substituted by a L-alanine (A), was described as exhibiting similar properties to synthetic thermoplastic elastomers [4,5] and was previously chemically synthesized by Rodríguez-Cabello and co-workers $[3,6]$. The same group reported its characterization, demonstrating its extreme biocompatibility both in vitro and in 
vivo, as well as its ability to self-assemble, forming microparticles that can entrap active substances during the self-assembling process $[3,6]$.

Advances in recombinant DNA technology has allowed the biological synthesis of large Molecular Weight (MW) engineered protein polymers containing repeating blocks of amino acids with precise composition, sequence and length, resulting on an absolute control of MW and stereochemistry. The present work describes the biological production of the poly(VPAVG) using standard molecular genetic tools. A higher molecular weight polymer containing 220 repeats of VPAVG sequence, with an estimated MW of $96 \mathrm{kDa}$ was expressed in Escherichia coli pET25 vector, followed by purification and characterization. The fermentation conditions were optimized using a Central Composite Design (CCD) approach to design the culture media.

\section{Materials and Methods}

Gene construction. The DNA coding for a peptide monomer containing 20 repetitions of VPAVG and flanked by Eam1104I recognition sites was subjected to concatenation in order to obtain a multimeric unit. The multimeric block genes were obtained by recursive directional ligation in the cloning vector and the cloning strategy used was previously described and reported as the "Gutenberg Method" [7,8]. The design of the monomeric DNA sequence took into account Escherichia coli codon usage and DNA-repetitive sequences were avoided. All the constructions/concatenation were performed in a modified cloning vector, pDrive (Qiagen) and transformed into E. coli strain XL1 Blue (Novagen). Constructions were confirmed with the restriction enzymes Eam1104I and EcoRI (Fermentas). Taq DNA polymerase, LguI restriction enzyme and GENERULER ${ }^{\mathrm{TM}} 1 \mathrm{~kb}$ DNA ladder were obtained from Fermentas. 100bp DNA ladder was purchased from Invitrogen and high marker from Bioventures. Vector dephosphorylation by anthartic phosphatase (New England Biolab) was performed prior to ligation with T4 DNA ligase (Roche). The plasmid extraction was performed with GENELUTE ${ }^{\mathrm{TM}}$ Plasmid Miniprep Kit (SigmaAldrich) and the DNA purification from agarose gel by NUCLEOSPIN ${ }^{\mathrm{TM}}$ Extract (MachereyNagel). Plasmids were selected based on their insert length and subcloned into a modified pET25b $(+)$ expression vector (Novagen) without any tags. The construction was confirmed by sequencing and restriction with endonucleases NdeI and XhoI (Fermentas). Agarose gel images were acquired with Eagle Eye II system and Eagle Sight software (Stratagene). The plasmid construct was verified by DNA sequencing. The sequencing was performed following the method of Sanger et al. [9], using an ABI PRISM 310 Genetic Analyzer. The vector carrying (VPAVG) 220 gene was used to transform E. coli strain XL1 Blue, according to the SEM method [10]. DNA cloning and manipulation were performed according to standard protocols [11]. The recombinant plasmids were then transformed into the expression strain E. coli BL21(DE3) (Novagen), followed by protein production with optimized medium.

Central composite design (CCD) and data analysis. The culture medium was formulated based on the recipes of several media, namely: Luria Bertani (LB), Terrific Broth with Phosphate Buffer and Glycerol (TB+PBG) [11] and salt medium from Teich and co-workers[12].

To analyze the production of (VPAVG) 220 , a central composite design with five coded levels was used for exploring the sub-region of the response surface in the neighborhood of the optimum. The three tested factors, glycerol, lactose and yeast extract concentrations (Table 1) were submitted to a $2^{3}$ factorial design, with values fluctuating from a central point $(0)$ to a lower level $(-1)$ and a higher level (+1). The three level combinations of the three factors define our experiment "nucleus" with three additional central points (where all the variables adopt the central value zero) in order to minimize the risk of losing the non-linear relations in the intervals and to allow the calculation of confidence intervals due to repetition $[13,14]$. The factors with negative values were considered as zero. The two responses considered were the concentrations of biomass and polymer obtained. The analysis of the obtained data, were performed using the software Design-Expert 6.0.6 (Stat-Ease, USA). The model adequacy was analyzed by the F value and the goodness of fit was expressed by 
the coefficient of determination $\mathrm{R}^{2}$. The significance levels were determined by values of "Prob > F" less than 0.05 .

Coded factors used in the CCD

\begin{tabular}{cccc} 
Run & $\begin{array}{c}\text { Glycerol } \\
{\left[\mathbf{g ~ L}^{-1}\right]}\end{array}$ & $\begin{array}{c}\text { Lactose } \\
{\left[\mathbf{g ~ L}^{-1}\right]}\end{array}$ & $\begin{array}{c}\text { Yeast Extract } \\
{\left[\mathbf{g ~ L}^{-1}\right]}\end{array}$ \\
\hline 1 & -1 & 1 & 1 \\
2 & 0 & 0 & $-1,68$ \\
3 & 1 & -1 & -1 \\
4 & -1 & -1 & -1 \\
5 & 0 & 0 & 0 \\
6 & 0 & 0 & 0 \\
7 & 0 & 0 & 1,68 \\
8 & 0 & 0 & 0 \\
9 & 1 & -1 & 1 \\
10 & 1 & 1 & -1 \\
11 & 0 & $-1,68$ & 0 \\
12 & 1 & 1 & 1 \\
13 & 0 & 1,68 & 0 \\
14 & $-1,68$ & 0 & 0 \\
15 & -1 & -1 & 1 \\
16 & -1 & 1 & -1 \\
17 & 1,68 & 0 & 0 \\
\hline
\end{tabular}

Table 1. Experimental range in coded factors of the three independent variables used in the CCD.

Polymer production and purification. Bacterial cultures were grown at $37{ }^{\circ} \mathrm{C}$ in optimized medium, containing $100 \mathrm{mg} / \mathrm{ml}$ ampicilin. After fermentation time of 16 hours, cells were harvested by centrifugation, washed with TBS $(20 \mathrm{mM}$ Tris, $140 \mathrm{mM} \mathrm{NaCl}$ at $\mathrm{pH} 8.0$ ), ressuspended in TE buffer (50mM Tris, $1 \mathrm{mM}$ EDTA at $\mathrm{pH} 8.0$ ) and lysed by ultrasonic disruption. The insoluble cell debris was removed by centrifugation at $4{ }^{\circ} \mathrm{C}$ and $10000 \mathrm{xg}$ for 20 minutes, preceded by a cooling step at $4{ }^{\circ} \mathrm{C}$ for 2-3 hours. As this polymer does not respond to $\mathrm{pH}$, the solution was adjusted to 3.5 with $\mathrm{HCl}$ in order to precipitate most of $E$. coli endogenous proteins, followed by a clearing centrifugation of 20 minutes at $10000 \mathrm{xg}$ and $4{ }^{\circ} \mathrm{C}$. The cleared supernatant was submitted to a heating stage (HS) of 30 minutes at $60{ }^{\circ} \mathrm{C}$, followed by a centrifugation at $40{ }^{\circ} \mathrm{C}$ to collect the aggregated polymer. The pellet was then ressuspended in $10-15 \mathrm{~mL}$ of cold deionised water and left at $4{ }^{\circ} \mathrm{C}$ for 2 hours, in a cooling stage (CS), in order to solubilize the aggregates. The HS and CS were repeated two more times followed by freeze-drying. Polymer fractions were analysed by SDSPAGE and stained with 0.3M Copper Chloride. SDS-PAGE gel images were acquired with Molecular Imager ChemiDoc XRS system and Quantity One software from Bio-Rad.

Maldi MS and MS/MS analysis of (VPAVG) ${ }_{220}$. The purity and amino acid sequence of $($ VPAVG) 220 was confirmed by mass spectrometry with previously digested polymer solutions. Possible cleavable enzymes were found by using the "PeptideCutter" application from ExPASy 
website (www.expasy.ch/tools/peptidecutter/). The digestion was carried out using proteinase $\mathrm{K}$ and standard protocols.

Turbidity and Differential Scanning Calorimeter (DSC). The turbidity experiments were conducted in a UV-Visible Thermo Spectronic Helios gamma spectrophotometer with a thermostatised sample chamber. The turbidity was assessed by the change in absorbance at 300nm for a $3 \mathrm{mg} / \mathrm{mL}$ polymer in water solution. The $T_{\mathrm{t}}$ was identified as the temperature at which $50 \%$ of turbidity had occurred. DSC experiments were performed on a Mettler Toledo DSC822e. Liquid nitrogen was used as cooler and the calibration of enthalpy and temperature was performed with Indium and Zinc. The analyses were carried in a solution of $25 \mathrm{mg} / \mathrm{mL}$ of polymer, either on deionised water, $\mathrm{NaCl}(0.2 \mathrm{M}, 0.4 \mathrm{M}, 0.6 \mathrm{M}$ and $0.8 \mathrm{M})$ and urea $(1 \mathrm{M}, 3 \mathrm{M}$ and $6 \mathrm{M})$. In a typical DSC run, $25 \mu \mathrm{l}$ of polymer solution were placed in a hermetically sealed aluminium pan and studied under a four-stage thermal program. First, the sample is treated 15 minutes at $4{ }^{\circ} \mathrm{C}$, followed by a heating stage (HS) from 4 to $60{ }^{\circ} \mathrm{C}$ with a constant heating rate of $+5{ }^{\circ} \mathrm{C} / \mathrm{min}$. The sample is maintained at $60{ }^{\circ} \mathrm{C}$ for 3 minutes and cooled down in a cooling stage (CS) to $-10{ }^{\circ} \mathrm{C}$ with a constant cooling rate of $-5^{\circ} \mathrm{C} / \mathrm{min}$. The onset and enthalpy $(\Delta \mathrm{H})$ values were calculated with the provided STARe software.

Preparation and morphological characterization of (VPAVG) 220 particles. A solution of $6 \mathrm{mg} / \mathrm{ml}$ of (VPAVG) 220 in water was treated at $40{ }^{\circ} \mathrm{C}$ over 40 minutes. Particles were formed by polymer self-aggregation from aqueous solution. The solution was then centrifuged at 11000xg and the supernatant discarded. The pellet was finally dried at $37{ }^{\circ} \mathrm{C}$ overnight. The mean size and distribution of (VPAVG) 220 was measured by Dynamic Light Scattering (DLS) with a Zetasizer Nano equipped with Dispersion Technology Software v5.02 from Malvern Industries. The morphological examination was performed on dried particles by Scanning Electron Microscopy (SEM).

\section{Results and Discussion}

Construction of poly VPAVG. The DNA monomer coding for 20 repetitions of the sequence VPAVG, including the Eam1104I recognition sites, with 300 nucleotides long was subjected to a concatenation reaction, creating a library of multimeric DNA units. The products of this reaction were cloned directly into pDrive vector, linearized with LguI. Fig. 1 represents the n-mer constructions obtained, $n=1, n=2, n=4, n=7$ and $n=11$, where $n$ represents the number of $(\mathrm{VPAVG})_{20}$ repetitions. The correct constructions were confirmed by restriction analysis with EcoRI and Eam1104I. Restriction with Eam1104I resulted on fragments with 300, 600, 1200, 2100 and $3300 \mathrm{bp}$, corresponding to the different multimeric blocks plus additional bands generated by Eam1104I vector digestion. EcoRI cuts pDrive in the flanking regions near the gene originating two fragments, one corresponding to the cloning vector (approximately 3900bp) and another one that varies depending on the size of the concatemer. A 220 repeats construct, coding for a polymer with an estimated molecular mass of $93 \mathrm{kDa}$, was obtained and subcloned into a modified pET25b (+) expression vector. The correct construct (pET-220) was confirmed by DNA sequencing and restriction with NdeI and XhoI endonucleases (data not shown), and used to transform E. coli strain BL21(DE3). 
A

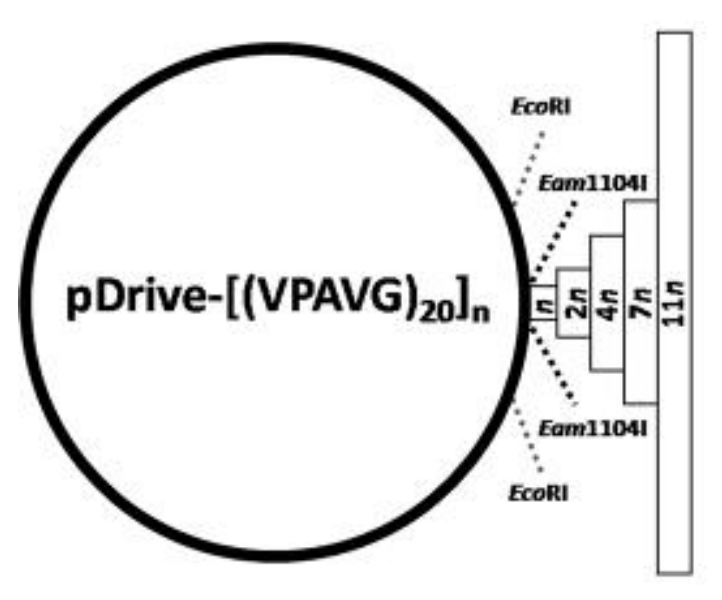

B

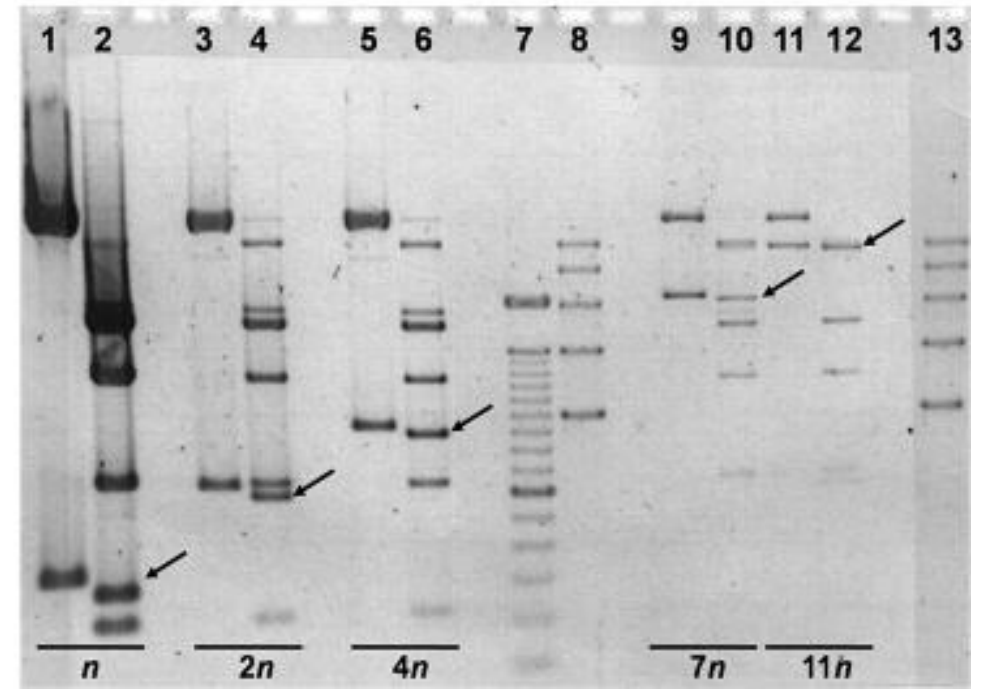

Fig. 1. A - Schematic representation of pDrive vector originating a library of n-mer VPAVG coding

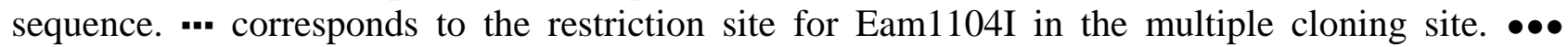
corresponds to the restriction site for EcoRI. B - Agarose gel electrophoresis of DNA constructions containing $\mathrm{n}$ (lanes 1,2$), 2 \mathrm{n}(3,4), 4 \mathrm{n}(5,6), 7 \mathrm{n}(9,10)$ and $11 \mathrm{n}(11,12)$, being $\mathrm{n}$ a 300 nucleotides long molecule coding for 20 repetitions of the sequence VPAVG, including the Eam1104I recognition sites. Lanes 1, 3, 5, 9, 11 - DNA restriction with EcoRI; lanes 2, 4, 6, 10, 12 - DNA restriction with Eam1104I; lane 7, 8 and 13 - molecular weight marker. The arrow indicates the respective cloned fragments.

CCD optimization. Preliminary fermentations with E. coli transformed with pET-220 in LB medium (induction at $\mathrm{DO}_{600}=0.6$ with $1 \mathrm{mM}$ IPTG and fermentation times of 5 and 24 hours) resulted in a production of $\sim 2 \mathrm{mg} / \mathrm{L}$ and showed that the biomass and polymer productions were closely related (data not shown), suggesting that an optimization of biomass production would be an approach to enhance the polymer production. In order to increase the production of (VPAVG) 220 and biomass formation, the levels of the variables glycerol (A), lactose (B) and yeast extract (C) were selected according to the results of previous experiments. Fig. 2 shows the response surface plots for the biomass production indicating that the higher of this parameter were achieved for glycerol and yeast extract concentrations at the middle and maximum of the experimental range, respectively and in the absence of lactose. The model for the polymer response was not significant statistically and therefore could not undergo validation. A first order coded model was established describing the biomass concentration as a function of glycerol, lactose and yeast extract concentrations:

$$
\text { Biomass }=3.38+0.056 \mathrm{~A}-0.17 \mathrm{~B}+0.63 \mathrm{C} \text {. }
$$

The goodness of fit was expressed by the coefficient of determination $\mathrm{R}^{2}$ calculated to be 0.55 , indicating that $55 \%$ of the variability of the response biomass could be explained by this model. The tests of lack of fit were not significant indicating that the model fits to the experimental results. The statistical significance of the second order model function was evaluated by the F-test analysis of variance which revealed that this regression is statistically significant. Based on the CCD results, the optimum medium composition for growing $E$. coli consisted of: $7.39 \mathrm{~g} . \mathrm{L}^{-1}$ of glycerol, $23.25 \mathrm{~g} . \mathrm{L}^{-}$ 1 of yeast extract, $0.5 \mathrm{~g} . \mathrm{L}^{-1}$ of glucose, $12 \mathrm{~g} . \mathrm{L}^{-1}$ of tryptone, $2.31 \mathrm{~g} . \mathrm{L}^{-1}$ of $\mathrm{KH}_{2} \mathrm{PO}_{4}, 12.54 \mathrm{~g} . \mathrm{L}^{-1}$ of $\mathrm{K}_{2} \mathrm{HPO}_{4} .3 \mathrm{H}_{2} \mathrm{O}, 0.5 \mathrm{~g} . \mathrm{L}^{-1}$ of $\mathrm{MgSO}_{4} .7 \mathrm{H}_{2} \mathrm{O}, 1.5 \mathrm{~g} . \mathrm{L}^{-1}$ of $\mathrm{NH}_{4} \mathrm{Cl}, 3.85 \mathrm{~g} . \mathrm{L}^{-1}$ of $\left(\mathrm{NH}_{4}\right)_{2} \mathrm{SO}_{4}, 0.5 \mathrm{~g} . \mathrm{L}^{-1} \mathrm{NaCl}$ 
and $8 \mathrm{~g} . \mathrm{L}^{-1}$ of $\mathrm{NaH}_{2} \mathrm{PO}_{4} \cdot \mathrm{H}_{2} \mathrm{O}$. This new medium recipe allowed the achievement of $\sim 6 \mathrm{mg} . \mathrm{L}^{-1}$ of polymer.
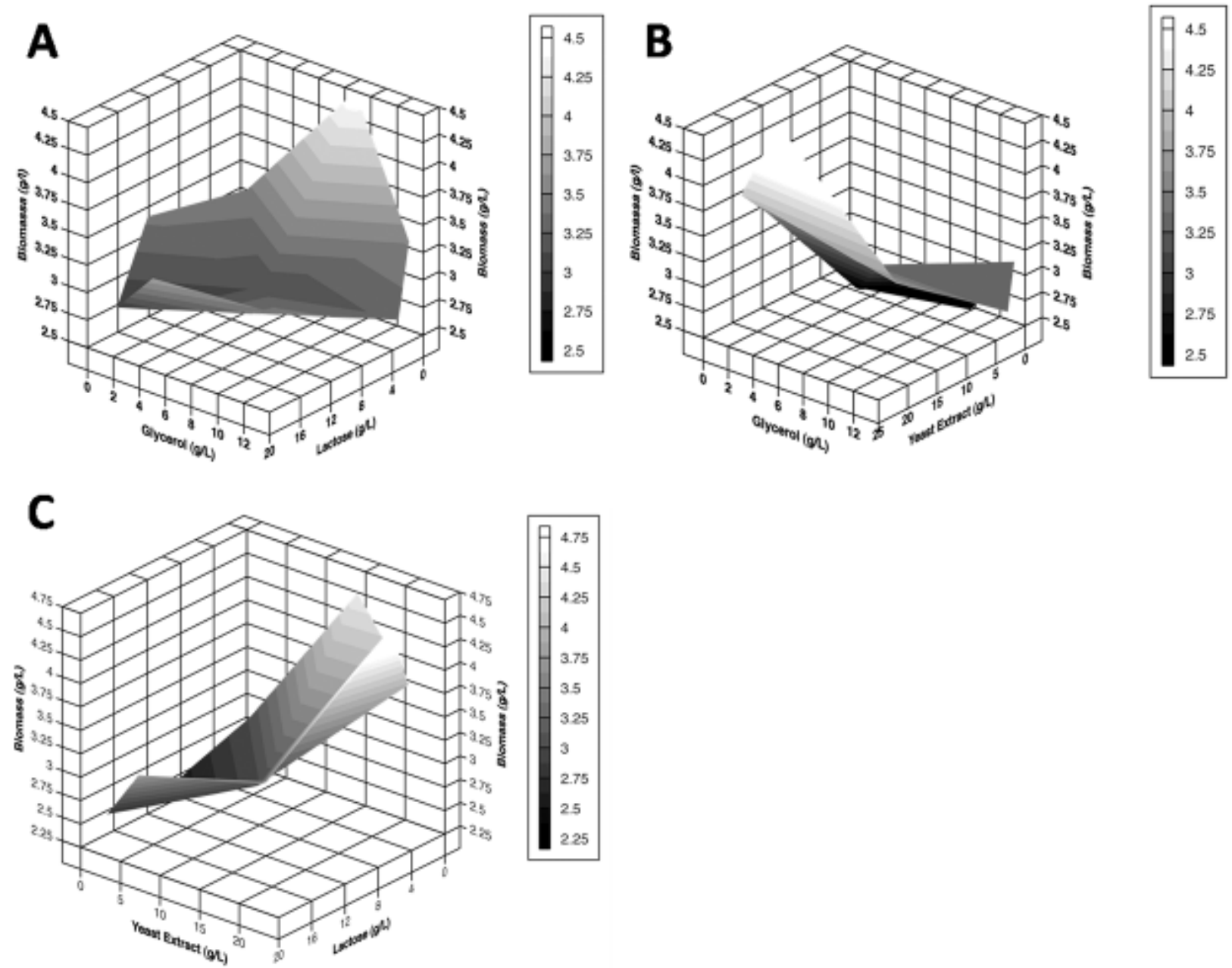

Fig. 2 - Response surface plots showing the production of biomass from E. coli and the interaction between glycerol $v s$ lactose (A), glycerol $v s$ yeast extract (B) and yeast extract $v s$ lactose (C).

Production and Purification of (VPAVG) 220 . Several E. coli transformants with pET-220 were selected and screened for production (data not shown) prior to fermentation conditions. The cells were harvested, lysed and the polymer purified as described in Material and Methods, based in simple hot and cold centrifugation steps (Fig. 3A). The polymer self-aggregates when the temperature rises above its $T_{\mathrm{t}}$, allowing its collection from solution by hot centrifugation. As the self-aggregation of the polymer is a reversible reaction, the polymer could be resolubilized in cold deionized water, while the denatured and aggregating contaminating biomolecules remain in solution, being further separated by cold centrifugation. Preparations of fully purified polymer (Fig. 3B) were lyophilized and used for characterization experiments. 


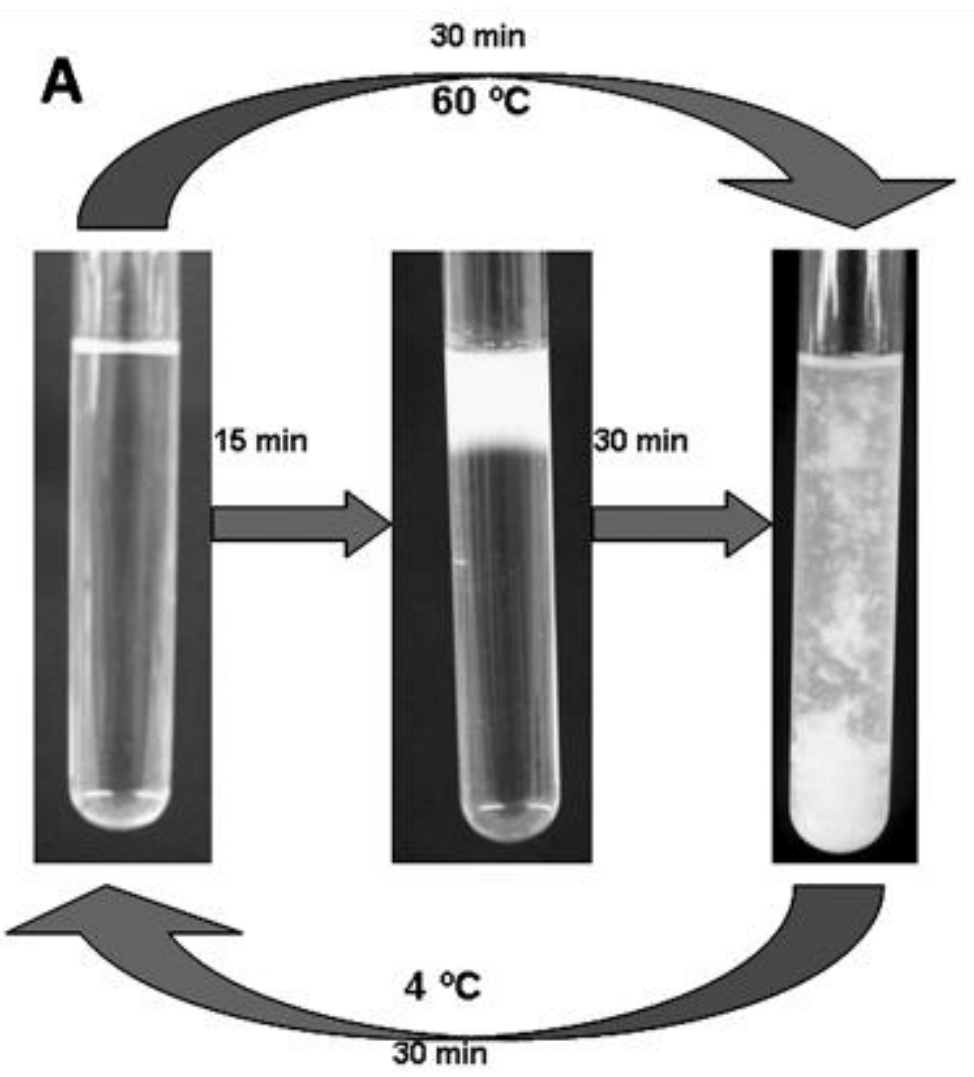

B

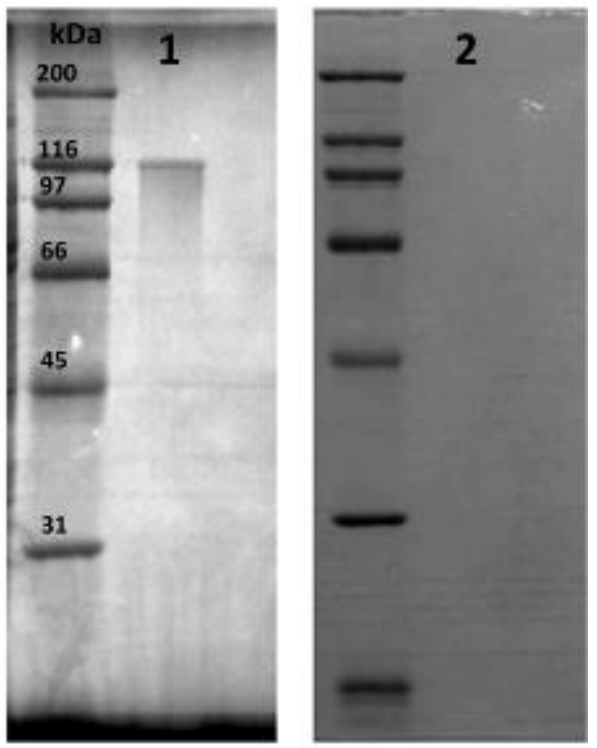

Fig. 3 - Purification of (VPAVG) 220 polymer. A - Behaviour of (VPAVG) 220 polymer solution submitted to hot and cold stages. After 30 minutes of incubation at $60{ }^{\circ} \mathrm{C}$ the polymer selfassembles, forming particles that come out of solution and solubilized again when submitted at 4 ${ }^{\circ} \mathrm{C}$. B $-10 \%$ SDS-PAGE analysis of purified (VPAVG) 220 polymer stained with copper chloride (lane 1) or with Coomassie staining (lane 2). As ELPs stain very poorly with Coomassie [24, 25], copper staining was used as routine protocol and Coomassie staining as negative control. The purified band appears with higher molecular weight than the expected, a phenomenon observed previously by McPherson et al. [24]. The molecular weight marker is the same for both gels.

Maldi MS and MS/MS analysis of (VPAVG) 220. The correct molecular weight, composition and sequence of the pure bioproduced polymer were assessed by MALDI-TOF/MS (data not shown) and MALDI-TOF MS/MS analysis. The polymer was digested with proteinase $\mathrm{K}$ in order to obtain small fragments of the protein followed by MALDI-TOF analysis. The spectra of the digested product revealed several peaks corresponding to the different fragments obtained (Fig. 4A). A fragment of 442.2Da corresponding to the theoretical molecular weight of a single VGVPA (proteinase $\mathrm{K}$ cuts between the $\mathrm{A}$ and $\mathrm{V}$ ) unit was selected and submitted to tandem MS to inspect the constitution and sequence (Fig. 4B) that was determined as Val-Gly-Val-Pro-Ala. The obtained sequence correlates with the prediction using the peptide cutter website when digesting $(\mathrm{VPAVG})_{220}$ with proteinase $\mathrm{K}$. 

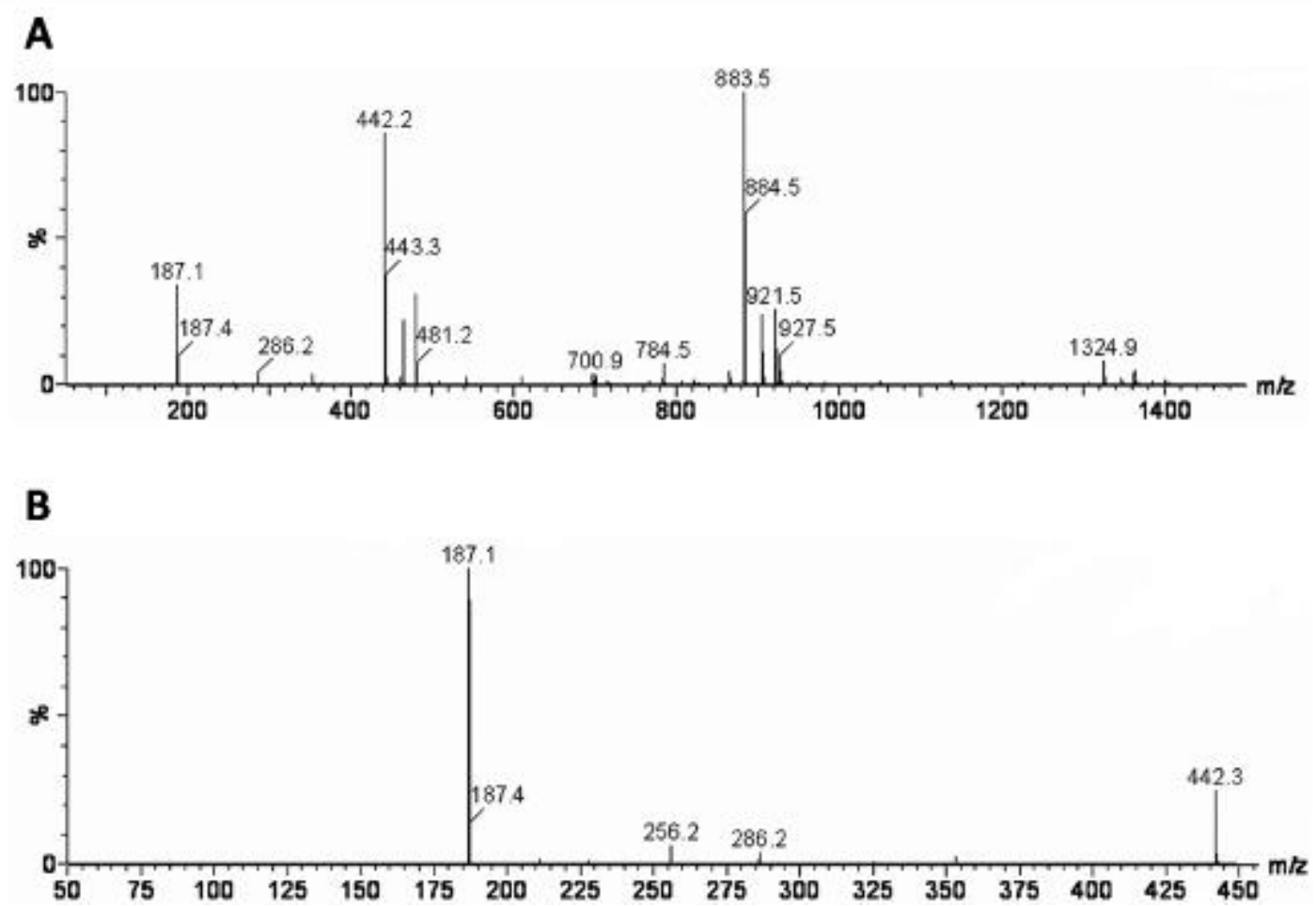

Fig. 4 - Mass spectra (MALDI-TOF/MS and MS/MS) of (VPAVG) 220 digests. A - Spectrum obtained from MS analysis of products digestion. The different signals correspond to the different length products, e.g. the signal at 187.1 Da corresponds to the PA product, 442.2 Da, corresponds to the VPAVG block and the signal at $883.5 \mathrm{Da}$ to a double VGVPA block. B - Spectrum obtained from tandem MS analysis of the 442.2 product. The spectrum analysis revealed the VGVPA sequence.

Turbidity and DSC analysis. Fig. 5 shows the results obtained in the DSC experiments, carried out with the cyclic program described in Materials and Methods, for a $25 \mathrm{mg} / \mathrm{mL}$ polymer solution in deionised water and $\mathrm{NaCl}$ at different concentrations.
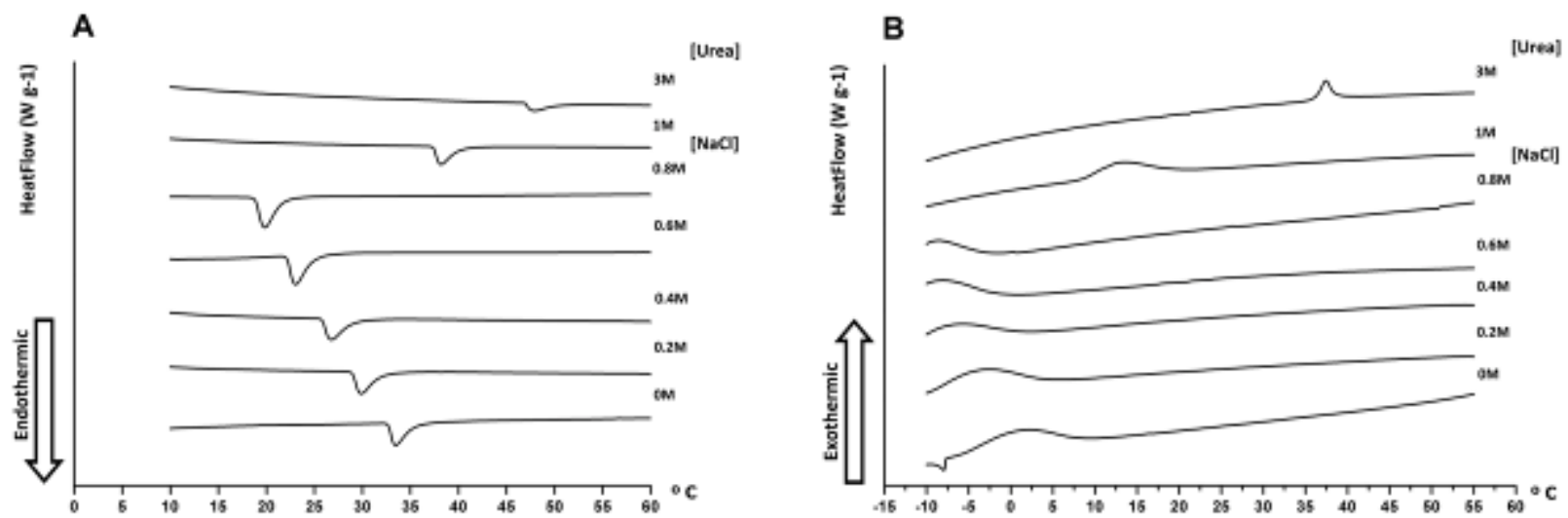

Fig. 5 - DSC run with $25 \mathrm{mg} / \mathrm{mL}$ polymer solution in different salt concentration solutions. A DSC heating stage with $+5^{\circ} \mathrm{C} / \mathrm{min}$ rate. $\mathrm{B}-\mathrm{DSC}$ cooling stage with a rate of $-5^{\circ} \mathrm{C} / \mathrm{min}$.

During the heating stage (HS) (Fig. 5A), the DSC pattern clearly exhibits an endothermic peak that is associated with the characteristic endothermic process of chain folding, accompanied by the destruction of the ordered water structures of hydrophobic hydration [3,8,15-17]. Accordingly to 
Rodríguez-Cabello and co-workers [8], the chain folding consists in interchain hydrophobic contacts that cause the formation of aggregates that separate from solution. The temperature of selfassembling $\left(\mathrm{T}_{\mathrm{t} \mathrm{S}}\right)$ was calculated based on the onset and is identified with the $T_{\mathrm{t}}$ (table II). On the contrary, an exothermic depression (Figure 5B) must be attributed to the reverse process, the unfolding of the polymer chain and rehydration of the ordered structures, leading to its consequent dissolution $\left(T_{t D}\right)$ [3,17]. However, there is a clear difference between the $T_{t S}$ and $T_{t D}$ of each condition, revealing hysteresis behaviour. As an example, the polymer self-assembles (folds) near $33{ }^{\circ} \mathrm{C}$ in deionized water but only redissolves when a strong undercooling is achieved.

Values of $\mathrm{T}_{\mathrm{tS}}$ and $\Delta \mathrm{H}$ calculated from the DSC experiment.

\begin{tabular}{lcc} 
Conditions & Onset of $\boldsymbol{T}_{\mathbf{t S}}\left[{ }^{\mathbf{}} \mathbf{C}\right]$ & Enthalpy $\mathbf{\Delta H}[\mathbf{J} / \mathbf{g}]$ \\
\hline Deionised water & 32.80 & 38.35 \\
$\mathrm{NaCl} \mathrm{0.2M}$ & 29.18 & 41.30 \\
$\mathrm{NaCl} \mathrm{0.4M}$ & 25.91 & 45.88 \\
$\mathrm{NaCl} \mathrm{0.6M}$ & 22.50 & 46.53 \\
$\mathrm{NaCl} \mathrm{0.8M}$ & 19.18 & 54.85 \\
Urea 1M & 37.55 & 31.14 \\
Urea 3M & 47.16 & 25.56 \\
Urea 6M & ---- & ---- \\
\hline
\end{tabular}

Table 2 - Values of $\mathrm{T}_{\mathrm{tS}}$ and $\Delta \mathrm{H}$ calculated from the onsets of the DSC run during the heating stage. The enthalpy $(\Delta \mathrm{H})$ of the endothermic process was calculated from the area of the endothermic peak.

In order to support the results obtained by the dynamic calorimeter study, a statical determination of $\mathrm{T}_{\mathrm{tS}}$ was carried out by turbidity assays. The plot in Fig. 6 represents the absorbance values obtained for a water solution of $(\mathrm{VPAVG})_{220}$. The $\mathrm{T}_{\mathrm{tS}}$ or $T_{\mathrm{t}}$ was determined as the temperature at which the turbidity reaches a value of $50 \%$, which was found to have a value of approximately $33{ }^{\circ} \mathrm{C}$. The rapid increase in turbidity upon reaching $\mathrm{T}_{\mathrm{t} S}$ shows that the transition is very sharp, occurring in a range less than $5{ }^{\circ} \mathrm{C}$. The small variation between the statical determination of $\mathrm{T}_{\mathrm{tS}}$ and the DSC results can be attributed to the associated thermal lags of the DSC experiment. 


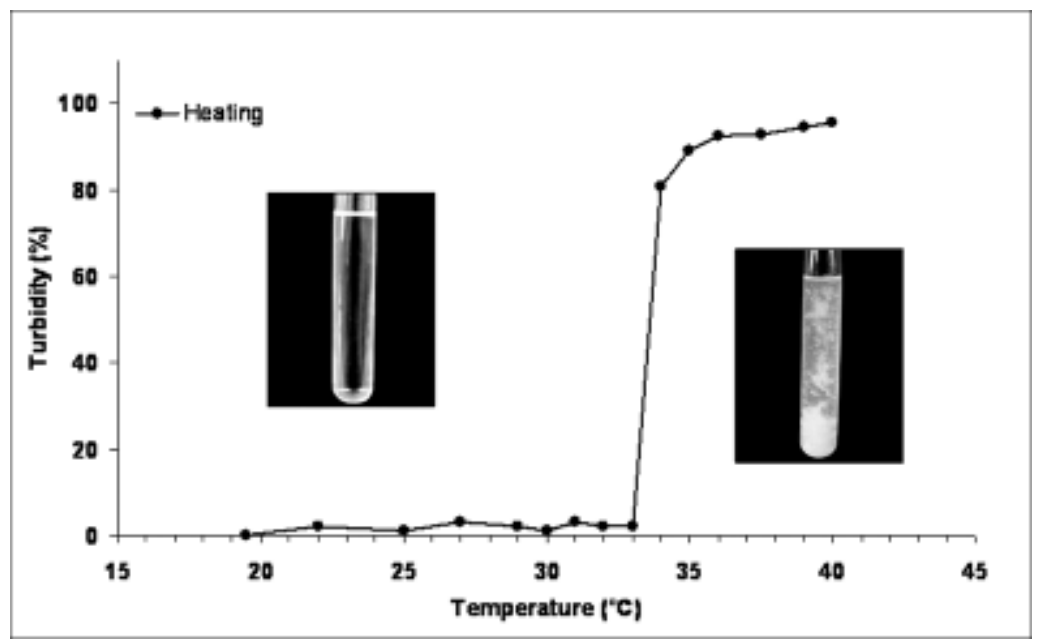

Fig. 6 - Temperature profile of aggregation during the heating process. The $T_{\mathrm{t}}$ was determined as the temperature at which the turbidty reaches a value of $50 \%$. The images shows the polymer solution below (in the left) and above (in the right) $T_{\mathrm{t}}$ and the formation of particles (in the right).

The hysteresis behaviour has been described in a previous work [18] with poly(VPGVG) and poly(VPAVG), as deduced from FTIR and Raman spectroscopies. It was suggested that this behaviour is a combination of two factors, the presence of a methyl group in the Ala residue in poly(VPAVG) and a more perfectly stable folding state when compared to the conventional poly(VPGVG). The methyl group in the Ala3 residue between the Pro2 and Val4, strongly influences the physical structure of the folded and unfolded states. In aqueous solution and below the $\mathrm{T}_{\mathrm{t} S}$, the water shell around poly(VPAVG) is more closely structured and thus it is more dissolved than poly(VPGVG). Above the $\mathrm{T}_{\mathrm{tS}}$, poly(VPAVG) contains less water bound to the carbonyl of amide groups than poly(VPGVG) [3,18], leading to a more compact and rigid structure due to the decrease in the plasticizing effect of water and its role in disrupting the intramolecular hydrogen bonds [8]. This impedes coacervation and causes the formation of stable particle suspension ${ }^{3}$. The presence of the methyl group is also fundamental for the reversibility of temperature transition. During the cooling, the unfolding process of poly(VPAVG) is hampered by the strongly bound amide groups that stabilize the folded structure and only takes place after strong undercoolings $[15,18]$.

It is well known that salts cause a significant, concentration-dependent, decrease in $T_{\mathrm{t}}$. Previous studies clearly shown that the $T_{\mathrm{t}}$ of ELPs is depressed by the addition of salts $[19,20]$. This fact is well represented in Fig. 5. When comparing the thermograms of the different conditions, there is a shift of the endothermic and exothermic components into lower temperatures as the salt concentration rises (for the endothermic peak: $33^{\circ} \mathrm{C}-\mathrm{H}_{2} \mathrm{O}, 29{ }^{\circ} \mathrm{C}-0.2 \mathrm{M} \mathrm{NaCl}, 26{ }^{\circ} \mathrm{C}-0.4 \mathrm{M}$ $\mathrm{NaCl}, 22.5^{\circ} \mathrm{C}-0.6 \mathrm{M}$ and $\left.19{ }^{\circ} \mathrm{C}-0.8 \mathrm{M}\right)$. The difference between the onset of the endothermic peaks can be explained by the ionic contribution of salt ions to the entropy of the system. Reguera et al. [20] demonstrated that there is a linear decrease in $T_{\mathrm{t}}$ versus the salt concentration $(\mathrm{NaCl})$, which is in agreement with our data. Accordingly, this behaviour can be explained by a complex process that involves not only the disruption of water structures and hydrophobic association, but also an increment in order in the main chain with a subsequent stabilization. The effect of $\mathrm{NaCl}$ concentration in the thermal parameter is equivalent to an increase in the hydrophobicity of the polymer and therefore, an increase in salt would cause an increase in the polarity of the solvent, causing more and more ordered structures surrounding the polymer chains. This fact provides an answer to the increasing values of enthalpy (Table 2) as the $\mathrm{NaCl}$ concentration raises and was previously observed by Reguera et al. [20]. The estimated enthalpy values $(\Delta \mathrm{H})$ for the ELP 
transition were endothermic and strongly influenced by the $\mathrm{NaCl}$ concentration, explainable by the increase in the number of more ordered structures of hydrophobic hydration surrounding the polymer chains.

In parallel to the calorimeter studies of $\mathrm{NaCl}$ and $\mathrm{H}_{2} \mathrm{O}$ polymer solutions, a DSC run was performed using polymer solutions with urea at different concentrations $(1 \mathrm{M}, 3 \mathrm{M}$ and $6 \mathrm{M})$. As expected, both endothermic and exothermic components shift to higher temperatures $\left(33{ }^{\circ} \mathrm{C}-\mathrm{H}_{2} \mathrm{O}, 37.5^{\circ} \mathrm{C}-\right.$ Urea $1 \mathrm{M}$ and $47^{\circ} \mathrm{C}$ - Urea $3 \mathrm{M}$ ), accompanied by a broadening of the endothermic peak (well represented between $1 \mathrm{M}$ and $3 \mathrm{M}$ urea polymer solutions). In the presence of urea $6 \mathrm{M}$ (data not shown) a straight line without any endothermic or exothermic components was observed, due to a flatted peak (broadening of the peak) or suggesting that a probable transition phase would occur outside the range of temperatures used $\left(4-60{ }^{\circ} \mathrm{C}\right)$. Urea at high concentrations is commonly used as a denaturing agent. This denaturation occurs because it diminishes the hydrophobic effect by displacing water in the solvation shell and specifically binds to amide groups through hydrogen bonds [21]. According to Urry [22] the addition of salts like $\mathrm{NaCl}$, lowers the $T_{\mathrm{t}}$, while the addition of urea or guanidinium chloride increases this value. Another work by Luan and Urry [23], carried with a synthetic poly(VPAVG), shows a raise in the $T_{\mathrm{t}}$ as the concentration of urea increases (34.2 ${ }^{\circ} \mathrm{C}, 38.5{ }^{\circ} \mathrm{C}, 43{ }^{\circ} \mathrm{C}$ and $48.5^{\circ} \mathrm{C}$ for $\mathrm{H}_{2} \mathrm{O}$, and urea $1 \mathrm{M}, 2 \mathrm{M}$ and $3 \mathrm{M}$, respectively) as well as a decrease in the sharpness of the endothermic peak. These results are in agreement with our data and suggest that the increasing urea concentration follows an almost linear increase in the $T_{\mathrm{t}}$. The enthalpy values (Table 2) calculated for the endothermic peak during the HS support the conclusions previously stated for the $\mathrm{NaCl}$ solutions. In opposition, while the addition of $\mathrm{NaCl}$ in the system leads to an increase in number of ordered structures, the addition of Urea disrupts the water of hydrophobic hydration, leading to a decrease in the hydrophobic effect.

Morphological characterization and size distribution by SEM and DLS analysis. The selfassembled (VPAVG) 220 particles resulted in sizes lower than $2 \mu \mathrm{m}$ as demonstrated by DLS analysis. Fig. 7 shows the volume diameter distribution (volume/size) of microparticles formed in water at $37^{\circ} \mathrm{C}$ from a $6 \mathrm{mg} / \mathrm{mL}$ polymer solution. These results correlate with previous work done with a chemically synthesised poly(VPAVG), that also demonstrated that there is a dependence between the heating rate and the mean size of microparticles [3].

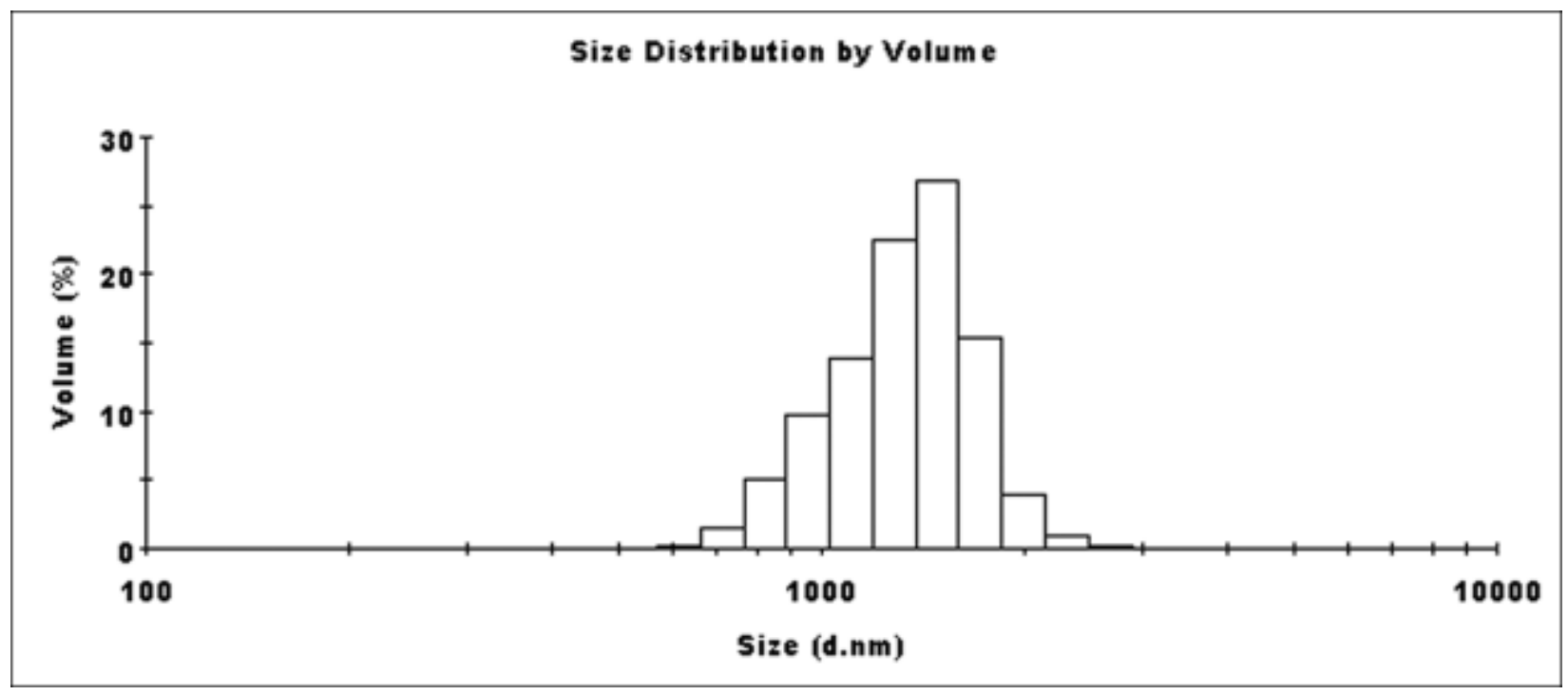

Fig. 7 - DLS analysis of volume diameter distribution of microparticles formed at $37^{\circ} \mathrm{C}$.

Fig. 8 shows micrographs of lyophilized/dehydrated polymer below and above the $T_{\mathrm{t}}$. Below the $T_{\mathrm{t}}$ the polymer appears in a disordered state without any structure conformation. On the other hand, in the situation above the $T_{\mathrm{t}}$, the polymer self-aggregates forming spherical particles. The size of 
particles appears to be smaller than those obtained by DLS, which can be explained by the drying step in the sample preparation procedure.
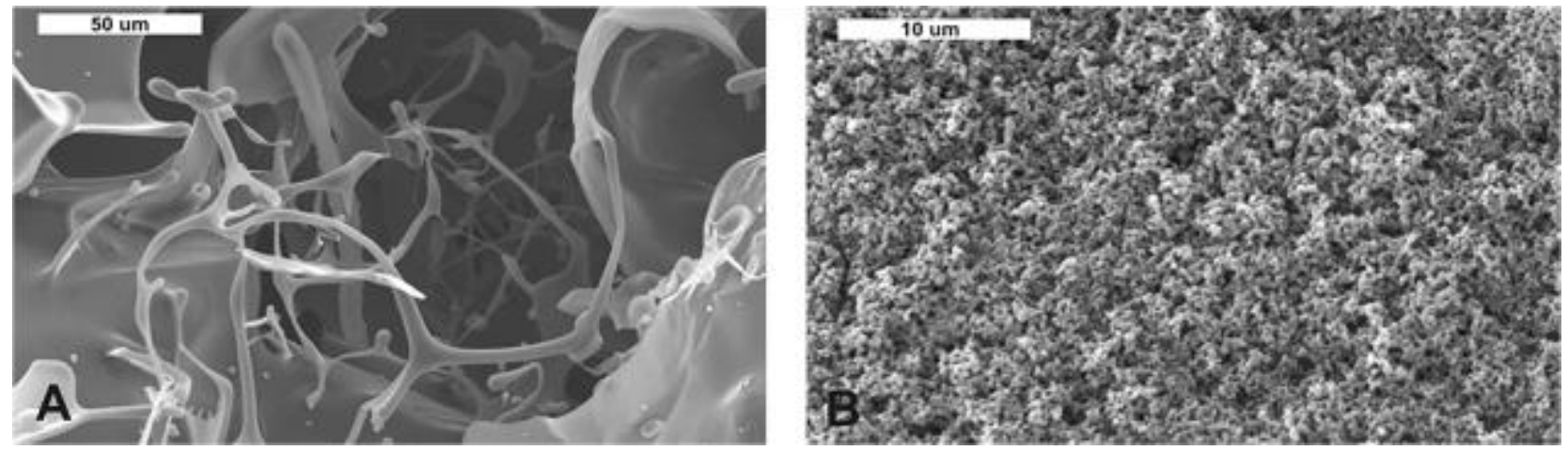

Fig. 8 - Micrographs of a lyophilized/dehydrated (VPAVG) 220 polymer below and above the $T_{\mathrm{t}}$. A SEM image showing the disordered state of a lyophilized polymer before the particle preparation (see Material and Methods) and below the $T_{\mathrm{t}}$. B - SEM image showing the size and shape of aggregates formed during the particle preparation (see Material and Methods) above the $T_{\mathrm{t}}$.

\section{Conclusions}

The use of genetic engineering tools allowed the obtention of protein-based polymers with an absolute control over their molecular weight and architecture. In this work and taking advantage of those tools, an ELP was designed and produced always keeping in mind maximal production with minimal low cost. Applying the CCD the media recipe was redesigned achieving a greater cell biomass minimizing the costs and increasing the final production from $2 \mathrm{mg} / \mathrm{L}$ to $6 \mathrm{mg} / \mathrm{L}$ of (VPAVG) 220 . Results from the DSC analysis showed a bio-produced polymer behaving the same way as the chemical synthesized. The influence of $\mathrm{NaCl}$ and Urea in the ITT of a VPAVG polymer was followed by conventional DSC showing that it is possible to modulate the $T_{\mathrm{t}}$ by exploiting the $\mathrm{NaCl}$ and Urea concentrations. According to the results obtained by DSC assays, the addition of $\mathrm{NaCl}$ causes a concentration-dependent decrease in the $T_{\mathrm{t}}$, with a subsequent increase in the $\Delta \mathrm{H}$. In opposition, the addition of Urea leads to an increase in the $T_{\mathrm{t}}$ and a subsequent decrease in the enthalpy. While the addition of $\mathrm{NaCl}$ to the system suggests that it leads to a better organization of the polymer when in the folded state and an increase in the number of ordered structures, the addition of Urea disrupts the bulk water, decreasing the hydrophobic effect.

When above its $T_{\mathrm{t}}$, the polymer self-assembles into spherical particles with a diameter distribution ranging from $700 \mathrm{~nm}$ to $2 \mu \mathrm{m}$. Further work will lay on drug delivery studies, focusing on hydrophobic compounds and the possibility of making biodegradable films.

Acknowledgements. This work was supported by the ElastM Project, POCI/CTM/57177/2004 from Fundação para a Ciência e Tecnologia (Portugal) and FEDER, "Junta de Castilla y Leon" (VA087A06, VA016B08 and VA030A08), MEC (MAT2007-66275-C02-01 and NAN200408538), and by the Marie Curie RTN Biopolysurf (MRTN-CN-2004-005516). Raul Machado received a PhD grant: SFRH/BD/36754/2007 from Fundação para a Ciência e Tecnologia (Portugal). The authors would like to thank Magda Graça (CBMA) for all the technical support in sequencing, Lígia Rodrigues for the CCD enlightenment and Dan W. Urry for the stimulating discussions and encouragement to pursue the studies on protein-based polymers.

\section{References}

[1] A. Simnick, D. Lim, D. Chow, A. Chilkoti, Journal of Macromolecular Science, Part C: Polymer Reviews. 47 (2007) 121-154. 
[2] D.W. Urry, D.C. Gowda, T.M. Parker, C.H. Luan, M.C. Reid, C.M. Harris, A. Pattanaik, R.D. Harris, Biopolymers. 32 (1992) 1243-1250.

[3] R. Herrero-Vanrell, A.C. Rincón, M. Alonso, V. Reboto, I.T. Molina-Martinez, J.C. RodríguezCabello, Journal of Controlled Release. 102 (2005) 113-122.

[4] J. Alper, Science. 297 (2002) 329-331.

[5] K. Nagapudi, W.T. Brinkman, J. Leisen, B.S. Thomas, E.R. Wright, C. Haller, X. Wu, R.P. Apkarian, V.P. Conticello, E.L. Chaikof, Macromolecules. 38 (2005) 345-354.

[6] A.C. Rincón, I.T. Molina-Martinez, B. de las Heras, M. Alonso, C. Baílez, J.C. RodíguezCabello, R. Herrero-Vanrell, Journal of Biomedical Materials Research Part A. 78A (2006) 343351.

[7] A. Girotti, J. Reguera, J.C. Rodríguez-Cabello, Journal of Materials Science: Materials in Medicine. 15 (2004) 479-484.

[8] J.C. Rodríguez-Cabello, J. Reguera, A. Girotti, M. Alonso, A.M. Testera, Progress in Polymer Science. 30 (2005) 1119-1145.

[9] F. Sanger, S. Nicklen, A.R. Coulson, Proceedings of the National Academy of Science. 74 (1977) 5463-5467.

[10] H. Inoue, H. Nojima, H. Okayama, Gene. 96 (1990) 23-28.

[11] J. Sambrook, D.W. Russel, T. Maniatis, Molecular Cloning: A Laboratory Manual, third ed., Cold Spring Harbour Laboratory Press, New York, 2001.

[12] M.I. Viitanen, A. Vasala, P. Neubauer, T. Alatossava, Microbial Cell Factories. 2 (2003) 1-10.

[13] D.C. Montgomery, Design and analysis of experiments, fifth ed., John Wiley \& Sons Inc., New York, 2001.

[14] L. Rodrigues, J. Teixeira, R. Oliveira, H.C. van der Mei, Process Biochemistry. 41 (2006) 110 .

[15] J. Reguera, J.M. Lagarón, M. Alonso, V. Reboto, B. Calvo, J.C. Rodríguez-Cabello, Macromolecules. 36 (2003) 8470-8476.

[16] J.C. Rodríguez-Cabello, J. Reguera, M. Alonso, T.M. Parker, D.T. McPherson, D.W. Urry, Chemical Physics Letters. 388 (2004) 127-131.

[17] J.C. Rodríguez-Cabello, Advances in Experimental Medicine and Biology. 553 (2004) 45-57.

[18] P. Schmidt, J. Dybal, J.C. Rodríguez-Cabello, V. Reboto, Biomacromolecules. 6 (2005) 697706.

[19] D.W. Urry, Journal of Physical Chemistry B. 101 (1997) 11007-11028.

[20] J. Reguera, D.W. Urry, T.M. Parker, D.T. McPherson, J.C. Rodríguez-Cabello, Biomacromolecules. 8 (2007) 354-358.

[21] Q. Zou, S.M. Habermann-Rottinghaus, K.P. Murphy, PROTEINS. 31 (1998) 107-115.

(22) D.W. Urry, Chemical Physics Letters. 399 (2004) 177-183.

(23) C.H. Luan, D.W. Urry, Journal of Physical Chemistry. 95 (1991) 7896- 7900.

(24) D.T. McPherson, C. Morrow, D.S. Minehan, J.G. Wu, E. Hunter, D.W. Urry, Biotechnology Progress. 8 (1992) 347-352.

(25) K. Trabbic-Carlson, L. Liu, B. Kim, A. Chilkoti, Protein Science. 13 (2004) 3274-3284. 


\section{Journal of Nano Research Vol. 6}

doi:10.4028/www.scientific.net/JNanoR.6

\section{Exploiting the Sequence of Naturally Occurring Elastin: Construction, Production and Characterization of a Recombinant Thermoplastic Protein-Based Polymer doi:10.4028/www.scientific.net/JNanoR.6.133}

\section{References}

[1] A. Simnick, D. Lim, D. Chow, A. Chilkoti, Journal of Macromolecular Science, Part C: Polymer Reviews. 47 (2007) 121-154.

[2] D.W. Urry, D.C. Gowda, T.M. Parker, C.H. Luan, M.C. Reid, C.M. Harris, A. Pattanaik, R.D. Harris, Biopolymers. 32 (1992) 1243-1250.

doi:10.1002/bip.360320913

PMid:1420991

[3] R. Herrero-Vanrell, A.C. Rincón, M. Alonso, V. Reboto, I.T. Molina-Martinez, J.C.

Rodríguez-Cabello, Journal of Controlled Release. 102 (2005) 113-122.

doi:10.1016/j.jconrel.2004.10.001

PMid:15653138

[4] J. Alper, Science. 297 (2002) 329-331.

doi:10.1126/science.297.5580.329

PMid:12130765

[5] K. Nagapudi, W.T. Brinkman, J. Leisen, B.S. Thomas, E.R. Wright, C. Haller, X. Wu, R.P. Apkarian, V.P. Conticello, E.L. Chaikof, Macromolecules. 38 (2005) 345-354. doi:10.1021/ma0491199

[6] A.C. Rincón, I.T. Molina-Martinez, B. de las Heras, M. Alonso, C. Baílez, J.C. RodíguezCabello, R. Herrero-Vanrell, Journal of Biomedical Materials Research Part A. 78A (2006) 343-351.

doi:10.1002/jbm.a.30702

[7] A. Girotti, J. Reguera, J.C. Rodríguez-Cabello, Journal of Materials Science: Materials in Medicine. 15 (2004) 479-484.

doi:10.1023/B:JMSM.0000021124.58688.7a

PMid:15332621

[8] J.C. Rodríguez-Cabello, J. Reguera, A. Girotti, M. Alonso, A.M. Testera, Progress in Polymer Science. 30 (2005) 1119-1145. doi:10.1016/j.progpolymsci.2005.07.004

[9] F. Sanger, S. Nicklen, A.R. Coulson, Proceedings of the National Academy of Science. 74 (1977) 5463-5467.

doi:10.1073/pnas.74.12.5463 
[10] H. Inoue, H. Nojima, H. Okayama, Gene. 96 (1990) 23-28.

doi:10.1016/0378-1119(90)90336-P

PMid:2265755

[11] J. Sambrook, D.W. Russel, T. Maniatis, Molecular Cloning: A Laboratory Manual, third ed., Cold Spring Harbour Laboratory Press, New York, 2001.

[12] M.I. Viitanen, A. Vasala, P. Neubauer, T. Alatossava, Microbial Cell Factories. 2 (2003) $1-10$.

doi:10.1186/1475-2859-2-2

PMid:12740045 PMCid:155635

[13] D.C. Montgomery, Design and analysis of experiments, fifth ed., John Wiley \& Sons Inc., New York, 2001.

[14] L. Rodrigues, J. Teixeira, R. Oliveira, H.C. van der Mei, Process Biochemistry. 41 (2006) 1-10.

doi:10.1016/j.procbio.2005.01.030

[15] J. Reguera, J.M. Lagarón, M. Alonso, V. Reboto, B. Calvo, J.C. Rodríguez-Cabello, Macromolecules. 36 (2003) 8470-8476.

doi:10.1021/ma034572q

[16] J.C. Rodríguez-Cabello, J. Reguera, M. Alonso, T.M. Parker, D.T. McPherson, D.W. Urry, Chemical Physics Letters. 388 (2004) 127-131.

doi:10.1016/j.cplett.2004.03.013

[17] J.C. Rodríguez-Cabello, Advances in Experimental Medicine and Biology. 553 (2004) 45-57.

[18] P. Schmidt, J. Dybal, J.C. Rodríguez-Cabello, V. Reboto, Biomacromolecules. 6 (2005) 697-706.

doi:10.1021/bm049461t

PMid:15762632

[19] D.W. Urry, Journal of Physical Chemistry B. 101 (1997) 11007-11028.

doi:10.1021/jp972167t

[20] J. Reguera, D.W. Urry, T.M. Parker, D.T. McPherson, J.C. Rodríguez-Cabello, Biomacromolecules. 8 (2007) 354-358.

doi:10.1021/bm060936l

PMid:17291058

[21] Q. Zou, S.M. Habermann-Rottinghaus, K.P. Murphy, PROTEINS. 31 (1998) 107-115.

doi:10.1002/(SICI)1097-0134(19980501)31:2<107::AID-PROT1>3.0.CO;2-J 
(22) D.W. Urry, Chemical Physics Letters. 399 (2004) 177-183.

(23) C.H. Luan, D.W. Urry, Journal of Physical Chemistry. 95 (1991) 7896- 7900. doi:10.1021/j100173a063

(24) D.T. McPherson, C. Morrow, D.S. Minehan, J.G. Wu, E. Hunter, D.W. Urry, Biotechnology Progress. 8 (1992) 347-352.

doi:10.1021/bp00016a012

PMid:1368456

(25) K. Trabbic-Carlson, L. Liu, B. Kim, A. Chilkoti, Protein Science. 13 (2004) 3274-3284. doi:10.1110/ps.04931604

PMid:15557268 PMCid:2287301 